\title{
Experiments with a Fire Math Model
}

\author{
H. W. EMMONS \\ Division of Applied Sciences \\ Harvard University \\ Cambridge, Massachusetts 02138, USA
}

\section{ABSTRACT}

Fire math models, solved via computer, are approaching sufficient generality to make performance fire codes practical. They are already adequate to explore the nature of fire resulting from a wide range of conditions. This investigation has examined the effect on the fire in an enclosure of the height of the fuel above the floor, the height of the doorway, the fire against a wall or in a corner, the size of the horizontal fuel slab, the total mass of fuel, the doorway width, the size of the room (from $1 / 4$ to 4 times), and the plume algorithm as predicted by the newest fire code FIRST ${ }^{12}$. The most important effect on the fire is the occurrence of oxygen starvation, all other effects axe relatively small. Because of space limitations, only the base fire and the effects of fuel height, doorway height, and the wall and corner are presented in some detajl here.

\section{INTRODUCTION}

There are two kinds of model, a physical model and a mathematical (math) model. A physical model is the hardware used in a test. A math model is a set of equations. A carefully performed test shows what really happens in the particular case tested. A math model permits the calculations of an approximation to what happens in a wide range of cases.

For fire safety engineering, models of both kinds have been used for years $(1-4)$. Most of this work was concerned with one component or another of the complex fire process. These studies involved flame speed ${ }^{5}$, diffusion flames ${ }^{6}$, charing solids ${ }^{7}$, plumes ${ }^{8}$, layering ${ }^{9}$, vent flows ${ }^{10}$, radiative heat transfer ${ }^{11}$, etc.

THE ENCLOSURE MATH MODEL

An enclosure math model is more than just tying together a series of component models, with some overall conservation equations. It requires extensive calculations of special cases to aisclose forgotten or unexpected interactions.

The latest fire math model in the U.S. is FIRST ${ }^{2}$, now being issued by the National Bureau of Standards. FIRST is an updated form of the Harvard Computer Fire code 5.3. The user must make two kinds of input. Information about the particular enclosure in which his fire will occur, 


\section{TABLE I}

The Bage Pire

Input default model for this study (all values, SI, ${ }^{\circ} \mathrm{K}$ )

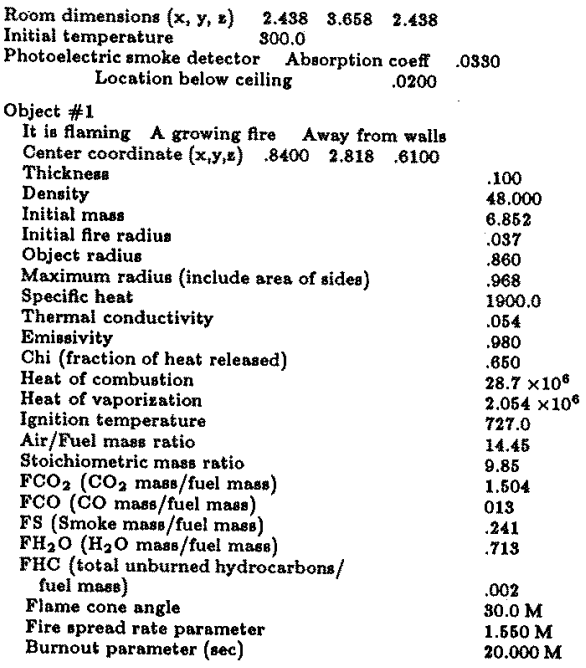

\begin{tabular}{|c|c|}
\hline $\begin{array}{l}\text { Tent \#1 } \\
\text { Width, Height, Depth } \\
\text { ceiling to mofit } \\
\text { Forced vent flow }\end{array}$ & .408 \\
\hline $\begin{array}{l}\text { Wall } \\
\text { Thicknese } \\
\text { Density } \\
\text { Specific heat } \\
\text { Thermal conductivity }\end{array}$ & $\begin{array}{l}.025 \\
800.0 \\
1082.0 \\
.194\end{array}$ \\
\hline $\begin{array}{l}\text { Physical Constants } \\
\text { External ambient temperature } \\
\text { Speciftc heat of air } \\
\text { Air heat transfer coefficient } \\
\text { Hot layer heat transer coeficient - } \\
\text { minimum (rises linearly } \\
\text { maximum in time) } \\
\text { Plume entrainment coefficient } \\
\text { Vent flow coefficient }\end{array}$ & $\begin{array}{l}300.0 \\
1004.0 \\
10.0 \mathrm{M} \\
\\
5.00 \mathrm{M} \\
50.00 \mathrm{M} \\
.100 \mathrm{M} \\
.680 \mathrm{M}\end{array}$ \\
\hline $\begin{array}{l}\text { Miacellaneous } \\
\text { Heating object conduction } \\
\text { surface temperature } \\
\text { Gas absorption coeffcient } \\
\text { Plume formula } \\
\text { TTY output interval } \\
\text { File output interval } \\
\text { Fire burning time } \\
\text { Maximum time atep } \\
\text { Minimum time atep } \\
\text { Tolerance } \\
\text { Iteration limit (by Gauss Seidel } \\
\text { before halving time step) }\end{array}$ & $\begin{array}{l}\text { 1D Differential } \\
\text { equation } \mathrm{M} \\
\text { By smoke } \mathrm{M} \\
\text { Area plume } \mathrm{M} \\
20.0 \mathrm{sec} \\
10.0 \mathrm{sec} \\
500.0 \mathrm{sec} \\
2.00 \mathrm{sec} \\
.00098 \mathrm{sec} \\
10^{-6}\end{array}$ \\
\hline
\end{tabular}

The $M$ indicates choices that should be determined by the relevant physical laws but because of our limited knowledge are left adjustable by the user. A change of one or more of these items changes the model while a change of an unmarked item changes the problem to be solved.

and certain adjustable physical constants. Nature has but one set of physical laws and no adjustable constants. When our knowledge of fire reaches maturity all adjustable constants will be chosen by the computer through the direct use of the relevant physical laws or completely validated empirical data. Each time a user changes a vent flow coefficient, or plume entrainment coefficient, or burnout time, the user is changing the model.

It is important that a user, especially now in the period of rapid development, know what his model does and does not do. Because of the complexity of fire interactions, there is no way to make clear what FIRST does and does not do in a paper of limited length. The best I can do is refer the reader to suitable references 3,14 .

One of the important uses of a comprehensive fire math model is to permit the exploration of the changes that result in a fire from changes of the fuel and its envixoment. This feature will be illustrated in the remainder of this paper.

\section{THE BASE FIRE}

Table 1 lists the 52 items of input data used as the base fire in this study of fire effects. (The remaining seven input items describe aspects of the numerical solution process to be used.) In particular the enclosure is $2.438,3.658,2.438 \mathrm{~m}(8,12,8 \mathrm{ft})$. The vent is a door 0.762 , 


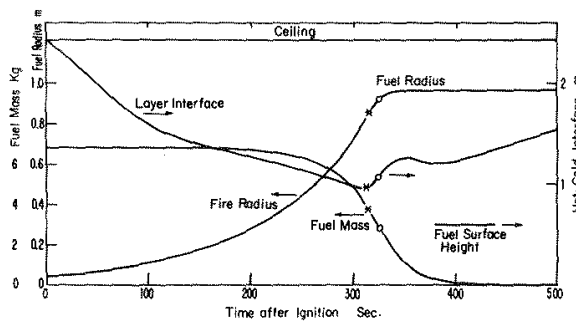

FTGURE 1. Base fire time variation of fuel mass, fire radius, and hotcold layer interface location above the floor.

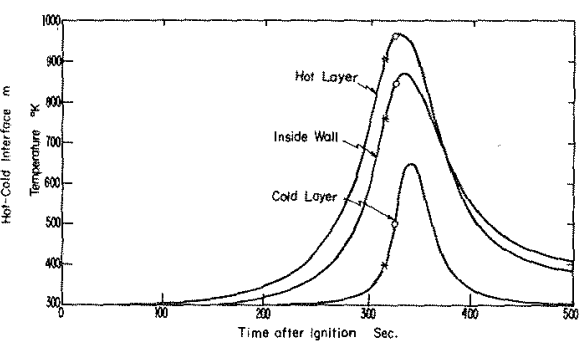

FIGURE 2. Base fire time variation of hot layer temperature, inside upper wall temperature, and the cold layer temperature

$2.032 \mathrm{~m}(30,80 \mathrm{in})$. The fuel is a polyurethane mattress $0.61 \mathrm{~m}$ (2ft) from the floor.

The fire information, output each chosen interval, contains 50 values of masses, energies, fire radius, layex temperature and depth, layer composition, vent flows, lower layer properties, heat fluxes, wall surface temperature, etc. To present figures or tables of all this information would require more than the permitted paper length. Instead, I show only a few of the more interesting properties of the fire as condensed as possible in Figures $1-5$.

The burning rate constant given in Table 1 was obtained by burning a fuel sample in a very large enclosure which had no room enexgy feedback effect and then interpreting this $r(t)$ data as a function of the computed feedback energy $q^{\prime \prime}(t)$ from an assumed conical $30^{\circ}$ apex angle cone.

A better way when possible is to burn the given fuel in an otherwise empty nonflammable enclosure. Then adjust the maximum radius, fuel height, and burning rate constant of FIRST to fit the measured $m(t)$, and $E(t)$ data. In this way the flat, round fuel of FIRST can serve well as simulating various irregular fuel complexes.

Since the fire grows at a rate proportional to the feedback energy, it starts from a small size (but not zero) at a slow rate and increases approximately exponentially as is evident in all the figures. However, the fire radius and mass loss are most important. As seen in Fig. 1, the radius increase slows down as the maximum radius is reached. This removes the sudden disappearance of radius growth that would otherwise appear. In this base fire, however, the phenomenon of oxygen starvation occurs at about the same time. The asterisk (*) indicates the time at which insufficient oxygen is entrained by the plume to burn all the pyrolysis fuel gases. This occurs when the hot layer is still $0.38 \mathrm{~m}$ above the fuel surface. In this base fire, the fuel mass is decreasing rapidly and these two effects cause the burning rate to peak (at $1.66 \mathrm{MW}$ ) as seen in Fig. 3. The result, Fig. 1, is a rise of the hot-cold layer interface and shortly thereafter an adequate oxygen supply to burn all the fuel gases indicated (o).

At about this same time, the 20 sec burnout process begins and further cuts back the burning rate. The interaction of all these effects cause the burnout period variation of the layer depth, Fig. 1, the flame heat flux to the fuel, Fig. 3, and the vent flows of $\mathrm{Fig}$. 4. Since the results 


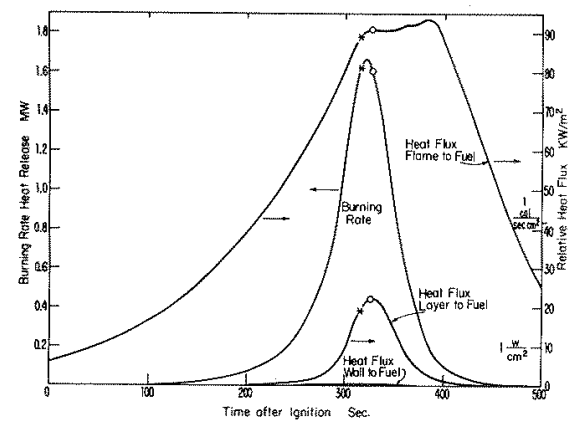

FIGURE 3. Base fire time variation of burning rate in $\mathrm{MW}$, the heat flux flame to fuel, the heat flux layer to fuel, and the heat flux upper wall and ceiling to fuel; all in $\mathrm{KW}$.

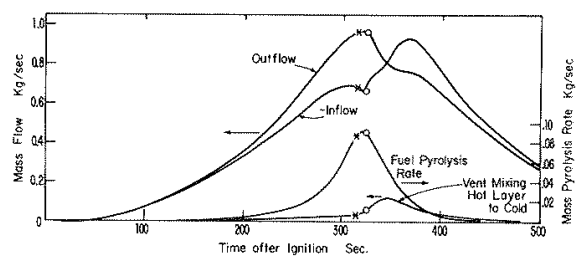

FIGURE 4. Base fire time variation of in and out vent flows, fuel pyrolysis rate, and hot to cold layer mixing rate at the vent.

during this period axe significantly influenced by the arbitrary burnout assumption, future research is needed to replace these arbitrary assumptions by better approximation of the real fire physics.

In Fig. 2, we see that the hot layer reaches $950^{\circ} \mathrm{K}$, about right for a model that does not burn the layer fuels. The cold layer, some 10 seconds later, reaches the maximum of $650^{\circ} \mathrm{K}$. This occurs through vent mixing of hot layer gas into the cold layer. The cold layer is thus heated but also contaminated with smoke which then further heats the cold layer by direct absorption of radiation. The additional heating process by radiative heat transfer to the floor and lower walls with subsequent convective heat transfer to the cold layer should be includod but has not yet been introduced into FIRST.

In Fig. 3 we see the heat fluxes to the fuel which provide the feedback energy. When the fuel vapors are burned the heat release rate is given by the burning rate curve. Note the scale differences. The pyrolyzing fluxes are in kilowatts while the burning rate is in megawatts--a scale 1000 times larger. Note that for this base fire the heat flux from its own flames dominates the feedback energy to the fuel. The hot layer is next in importance while the hot upper wall is insignificant. The fact that the hot walls are only $95^{\circ}$ coolex than the hot layer makes their insignificant feedback energy suspiciously low. It is correct, however, both because of the fourth power of temperature in the radiant heat transfer and the fact that the wall radiation passes through the smokey hot layer which absorbs a substantia! amount of the wall radiated energy. The fact that the flame radiation remains high some 60 seconds after the burning rate drops sharply is a defect in FIRST, was discovered by this work, and was caused by the Burnout parameter. It will be corrected in the next version of FIRST.

The vent flow rates of Fig. 4 result from the interaction of a number of effects. For the first 53.89 seconds there is flow out over the entire vent. This is caused by the gas expansion caused by the heat liberated by the fire, and the fact that the hot layer has not yet reached the door soffit. The layer reaches the soffit in 46.46 seconds but does not immediately remove enough air to accommodate the fire gas expansion. 


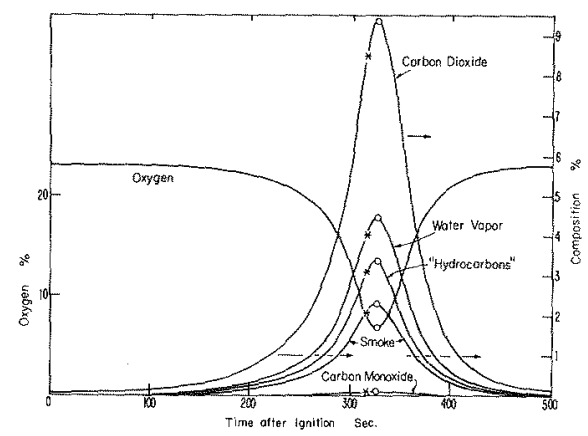

FIGURE 5. Base fire time variation of layer composition in $\mathrm{O}_{2}, \mathrm{CO}_{2}, \mathrm{H}_{2} \mathrm{O}$, "HC," CO, smoke.

After this initial period, the gas outflow has to remove the mass inflow plus the pyrolyzed fuel. At 260 seconds, the inflow $0.556 \mathrm{~kg} / \mathrm{sec}$ plus the pyrolyzed fuel 0.018 is $0.574 \mathrm{~kg} / \mathrm{sec}$ which is $0.102 \mathrm{~kg} / \mathrm{sec}$ short of the $0.676 \mathrm{~kg} / \mathrm{sec}$ outflow. This additional mass flow arises from the fact that the hot layer is getting deeper at the rate of $0.0032 \mathrm{~m} / \mathrm{sec}$ but more importantly its temperature is rising at the rate of $4.56^{\circ} \mathrm{k} / \mathrm{sec}$. Thus the increase of hot layer gas has less mass than the corresponding volume of cold air but also the expansion of the hot layer gas by the increase of temperature requires further gas outflow. The sudden increase of inflow which occurs at 324.5 seconds results from the rapid $x$ ise in the hot-cold interface. However, as a comparison of the layer height in $\mathrm{Fig}$. I and the inflow rate in Fig. 4 at 360 seconds shows, the inflow continues to increase even though the hot-cold interface is no longer rising. The reason is that the fuel is nearly gone, the burning rate is falling rapidly, $20 \mathrm{kw} / \mathrm{sec}$, and as a result the hot layer temperature is falling $6.6^{\circ} \mathrm{K} /$ second.

On examining Fig. 5, one is struck by the similarity of all the composition curves including the oxygen deficiency. The reason is clear since each compound is produced at a rate proportional to the fuel gas produced. This is not very accurate for a real fire but is the best that can be done with present empirical chemical knowledge.

What Happens as the Problem Changes?

Since there are 52 user set input variables defining the problem to be solved by FIRST, and there are--on average-five significant values of each variable, there are some $1.1 \times 10^{37}$ fires that may arise with FIRST with one object and one vent. With three objects and two vents a much larger number of fires are possible. Needless to say the 90 cases actually studied before this manuscript was due covers little of the actual potential of this fire computer program. Only a few of the interesting questions which have been examined are described in the remainder of this paper because of length limitations. In each case a set of time dependent curves comparable to Figs. I through 5 could be presented. This is clearly impractical. Therefore only the maximum of various vaxiables are presented.

Effect of Height of Fuel Above the Floor

As the fuel is raised, the plume is shortened, the entrained air is altered, and the layer properties and hence all resultant fire properties 


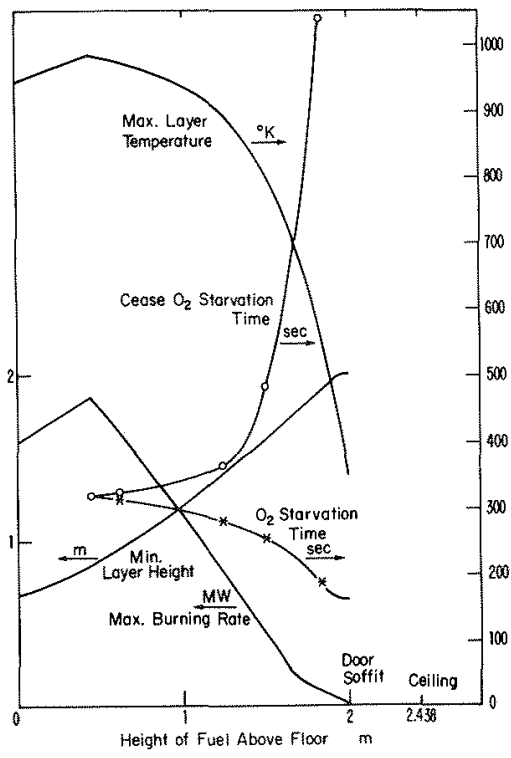

FIGURE 6. The effect of height of the fuel surface above the floor on the time of the start and cessation of $\mathrm{O}_{2}$ starvation, maximum layer temperature, maximum burning rate, and minimum layer height.

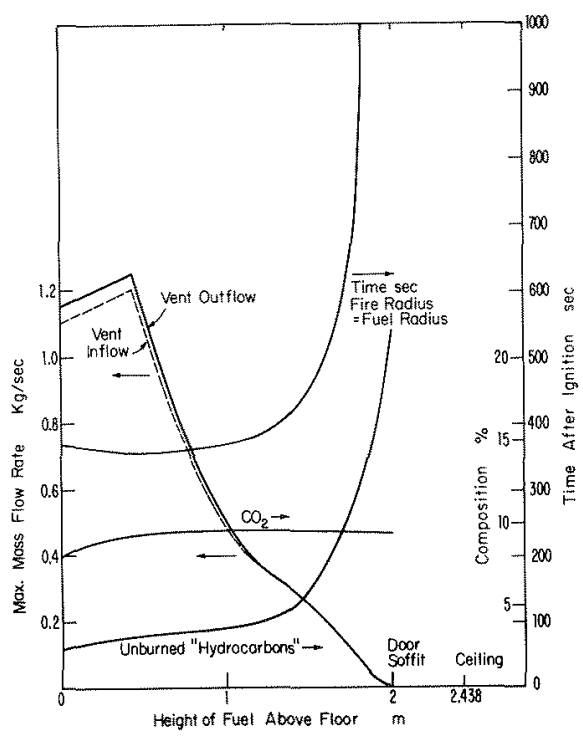

FIGURE 7. The effect of height of the fuel surface above the floor on the time the fire radius has grown to encompass the fuel, the maximum in and out vent flows, the maximum layer $\mathrm{CO}_{2} \%$, the maximum layer unburned "hydrocarbons."

are changed. When on the floor, the base fire object properties, primarily its mass and diameter, do not give rise to oxygen starvation. So long as no starvation exists, the layer temperature rises, fron $940^{\circ} \mathrm{K}$ with the fuel on the floor to $980^{\circ} \mathrm{K}$ with the fuel at 0.42 meters above the floor. For higher fuel surfaces the temperature falls as shown in Fig. 6 since there is decreasing $\mathrm{O}_{2}$ available.

The limit case of fuel at the height of the vent soffit, in this case $2.032 \mathrm{~m}$ above the floor, the fire grows as long as the layer has not fallen to the soffit during which time its temperature reaches $350^{\circ} \mathrm{K}$ and then gradually falls. The fire may actually extinguish.

The most important effect of the fuel height is the occurrence of oxygen starvation. At oxygen starvation the burning rate falls and the further fall of the hot-cold interface is checked. The time at which $\mathrm{O}_{2}$ starvation (*) and its cessation ( 0 ) occurs as affected by the fuel height are shown in Fig. 6. The maximum burning rate falls almost linearly with a $x$ ise of fuel surface so long as it is $\mathrm{O}_{2}$ starved.

The height of the fuel has a major effect on the vent flows, the rate at which the fire radius grows, and the hot layer composition as shown in Fig. 7. After the advent of oxygen starvation, both the inflow and outflow fall as the fuel surface rises, becoming zero when the fuel surface reaches the door soffit. Since the fire burns slower and slower as the 


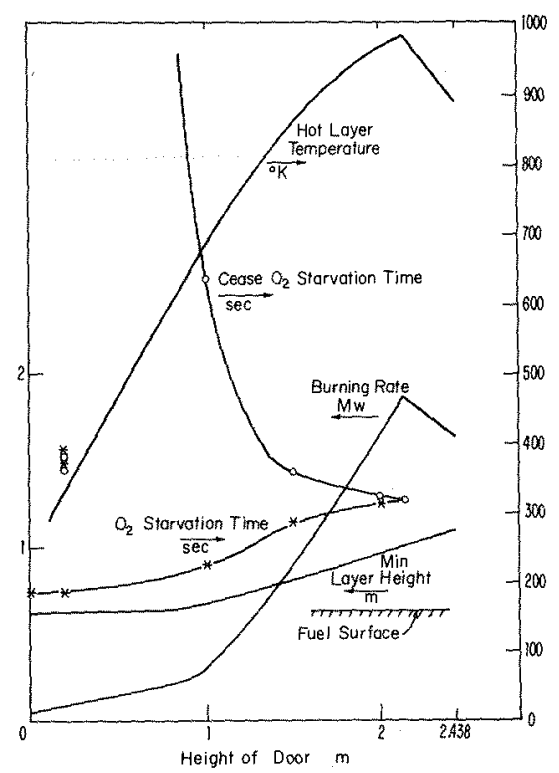

FIGURE 8. The effect of the height FIGURE 9. The effect of the height of of the door on the time of the start the door on the time the fire radius and cessation of $\mathrm{O}_{2}$ starvation, maximum layer temperature, maximum burning rate, and minimum layer height.

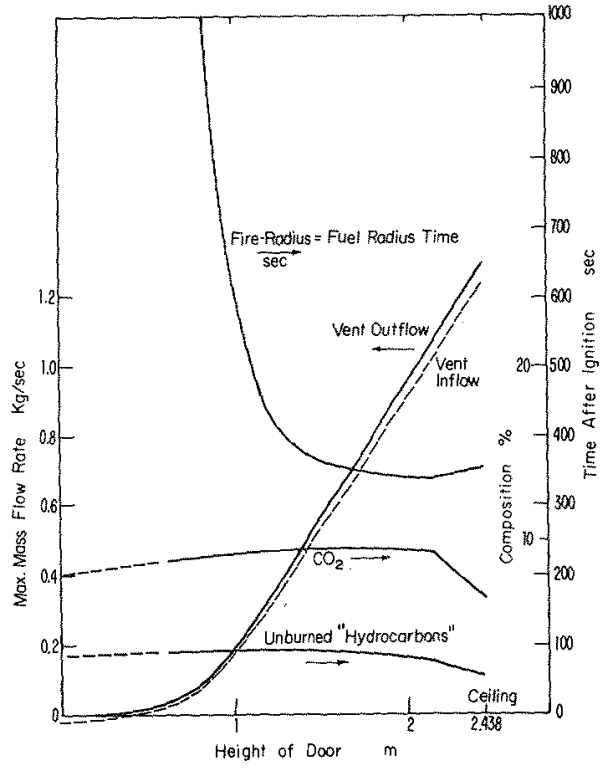

has grown to encompass the fuel, the maximum in and out flow through the vent, and the maximum layer $\mathrm{CO}_{2}$ \% and unburned "hydrocarbons."

fuel rises, it takes longer and longer for the fire to grow to the fuel radius.

The composition in all components proportional to the burning rate remain nearly constant like the $\mathrm{CO}_{2}$ of Fig. 7 . On the other hand the unburned "hydrocarbons" rise sharply because less and less of the pyrolyzed fuel gases are burned.

\section{Effect of Doorway Height}

A series of five runs were made with a vent of width $0.762 \mathrm{~m}$ and heights ranging from 0.01 to full room height $2.438 \mathrm{~m}$. Again the most important effect is the control of the hot layer depth since this in turn regulates the occurrence of oxygen starvation.

Figure 8 shows that so long as there is limited oxygen, the burning rate increases with doorway height. This occurs because the increased air entrainment in the higher plume burns the fuel vapors more completely resulting in a higher layer and hence higher radiation to the fuel. However, as soon as the layer is so high that oxygen starvation no longer occurs, the additional entrained air cools the hot layer which in turn decreases the feedback energy to the fuel.

We note in Fjg. 8 that oxygen starvation occurs later and at a higher layer interface for a higher doorway in spite of the fact that the fuel is 
TABLE 2

Percent change in maxima of various fire properties as the fuel is moved to a wall or to a corner

$\begin{array}{lccc} & \text { At Wall } & \text { In Corner } \\ \text { Burning rate } & -8.5 & -15.2 \\ \text { Doorway inflow } & -9.2 & -34.6 \\ \text { Doorway outflow } & -8.6 & -16.3 \\ \text { Layex temperature } & 6.7 & 6.3 \\ \text { Layer interface above floor } & -3.3 & -6.3 \\ \text { Time of oxygen starvation } & -3.2 & - & 5.1 \\ \text { Cease oxygen starvation } & 0 & 0 \\ \text { Time of fire starvation } & 0 & 0 \\ \mathrm{CO}_{2} \text { concentration } & 1.4 \% & 1.8 \% \\ \mathrm{HC} \text { concentration } & 16.0 \% & 18.0 \%\end{array}$

at a fixed height of $0.61 \mathrm{~m}$. This occurs because the higher vent gives a higher hot layer temperature, hence a higher fuel pyrolysis rate which in turn requires more oxygen for combusion.

Note that the cessation of $\mathrm{O}_{2}$ starvation occurs later and later as the hot layer approaches the level of the fuel. For doorways lower than the fuel, the $\mathrm{O}_{2}$ starvation frequently ceases and occurs in rapid succession as indicated at 360 secondt at a door height of $0.2 \mathrm{~m}$.

It has been suggested that a fire control measure would be a smoke detector operated automatic opening of the transom to the ceiling of a fire enclosure in order to let the hot layer out. This, it is alleged, will decrease the enclosure internal radiation transfers and slow the fire growth. In fact, as Fig. 8 shows the hot layer temperature falls by $8 \%$, the pyrolysis rate falls by at most $12.8 \%$ from their maximum values (fxom the normal doorway height it falls not at all because of plentiful air supply), and the hot layer interface rises only $10 \mathrm{~cm}$. This suggestion is a bad idea.

The results shown in Fig. 9 are as expected; namely, a high doorway permits higher vent mass flow rates and the high burning rates cause the fire to engulf the entire fuel surface more quickly. The effect on the hot layer composition is significant on both ends. For the doorway open to the ceiling, $i . e .$, above the $\mathrm{O}_{2}$ starvation level, all product gases as well as unburned "hydrocarbons" fall. In fact, for a $1 \mathrm{~cm}$ leak at the floor, the fuel burns initially as in all other cases but because the vent is so small there is outflow only. Therefore the hot layer falls to the surface of the fuel and no oxygen is entrained to burn the pyrolizate. In fact, when the hot layer comes within $5 \mathrm{~cm}$ of the fuel surface, the burning rate is so low that the hot layer begins to slowly cool. Its contraction reverses the flow through the vent which changes from slow outflow to slow inflow. This run emphasizes one of the weaknesses of EIRST. There should be burning in the hot layer since in this case it still contains $21 \%$ oxygen. The $\mathrm{CO}_{2}$ and "HC" compositions for doox heights less than the fuel height are shown dashed because the fire burns so slowly that the composition was still changing after 10 or 15 minutes of fire time.

The Effect of the wall and the corner

In FIRST, the user has the option of burning the fuel away from the enclosure walls, at the walls, or in a corner. This is accomplished in 
the simple approximate way of supposing that at the wall the fuel has twice the actual area and mass but that only half of it is in the room. The corner similarly has four times the area and mass but only $1 / 4$ is in the room. Since these approximate algorithms are independent of the actual fuel location, it does not actually have to be at the wall or in a corner. However, if there is any other fuel present to be heated to ignition, it would be important to put the burning object at the wall or in the corner so that the correct radiative view factors would be used by the computer.

Table 2 shows the effect of the fuel location on the maximum values of various physical quantities. The largest effect is on the vent flows, the burning rate, and the unburned "hydrocarbons." Because of the walls, the plume entrainment is decreased so that the vent flows are decreased and the layer temperature is increased. $\mathrm{O}_{2}$ starvation occurs sooner so that there is an increase of unburned "hydrocarbons." At the present time, FIRST does not have a ceiling jet nor does it compute the flames over the ceiling nor along the side walls. Even without these effects the interactions are too complex to make easy qualitative judgments possible. That the computed changes are of the right kind is indicated by the data in a recent paper. 15

\section{CONCLUSION}

The fire in an enclosure is computable for a wide range of conditions. The present math model, FIRST, is already adequate for use in satisfying a performance fixe code for those phenomena it includes. However, it still. needs fuel pyrolysis prior to ignition, a wall fire, ceiling pyrolysis, plume burning in the hot layer, a nonsteady ceiling jet, and a hot layer burnout before a performance code could be satisfactorily complied with. The present math model is adequate to study many fire problems as illustrated by the few cases presented here. Many more cases have been examined but are too lengthy for the present paper.

\section{KEY WORDS}

Fire models, mathematical models, compartment fires. 
REFERENCES

1. Quintiere, J.G., McCaffrey, B.J., and Harkleroad, M. The Burning of Wood and Plastic Cribs in an Enclsoure, Vol. I and II, NBSIR 80-2054, 1980.

2. Croce, P.A., et al., A study of Room Fire Development, Vol. 1, 2, 3, Factory Mutual Research Corp., Serial No. 210011.4, 21011.6, 21011.7, $1974,1975,1976,1977$.

3. Emmons, H.W., "The Calculation of a Fire in a Large Building," J. Heat Transfer, 105, 151-158, 1983.

4. Visich, M., "Consideration of Fire Development in an Enclosed Space," J. Environ. Sys., 3 (3), 215-231, 1973.

5. Hirshfelder, J.O., et al., "Theory of propagation of Flames, Parts I, II, III," Third International Symposium on Combustion, 121-140, 1949.

6. Bilger, R.W., "Turbulent Jet Diffusion Flames," Prog. in Energy and Combustion Sci. I, 87-109, 1976.

7. Kung, H.C., "A Mathematical Model of Wood Pyrolysis," Comb. and Flame $18,185-195,1972$.

8. Zukoski, E.E., Kubota, T., and Cetegen, B.M., "Entrainment in Fire Plumes," Fire Safety J. 3, 107-121, 1980.

9. Steckler, K.D., Quintiere, J.G., and Rinkinen, W.J., "Flow Induced by a Fire in a Compartment," NBSIR 82-2520, P. 91, 1982.

10. Prahl, J. and Emmons, H.W., "Fire Induced Flow Through an Opening," Comb. and Flame, 25 (3), 369-385, 1975.

11. deRis, J., "Fixe Radiation--A Review," 17th International Symposium on Combustion, pp. 1003-1016, 1978.

12. Mitler, H.E. and Rockett, J.A., "User's Guide to FIRST, A Comprehensive Single-Room Fire Model, NBSIR 87-3595, 1987.

13. Mitler, H.E. and Emmons, H.W., "Documentation for Computer Fire Code $V$-The Fifth Harvard Computer Fire Code, NBS-GCR-81-344, pp. 1-183, 1981 .

14. Mitler, H.E., "The Physical Basis for the Harvard Computer Fire Code," Home Fire Project Technical Report \#34, Division of Applied Sciences, Harvard University, pp. 0-91, 1978.

15. Mower, F.W. and Williamson, R.B., "Estimating Room Temperatures from Fixes Along Walls and in Corners," Fire Technology 23 (2), 133-146, 1987 .

List of symbols

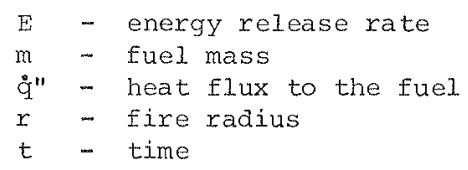

